\title{
Development of mangrove tourism area through making tourism umbrellas as well as private society preparation in Regemuk village Pantai Labu Sub-Distric Deli Serdang District
}

\author{
Darma Bakti ${ }^{*}$, Rosmayati ${ }^{1}$, Nini Rahmawati ${ }^{1}$ \\ ${ }^{1}$ Faculty of Agriculture, Universitas Sumatera Utara, Medan, Indonesia \\ *Email:dbakti06@yahoo.com
}

\begin{abstract}
Regemuk Village has the potential to be developed into a new tourist destination village. The village which is located along the coastline of Deli Serdang Regency is geographically the closest village to Medan City and the location is adjacent to Kuala Namu Airport. One of the advantages of this village is the presence of a stretch of mangrove forest which is still quite good along the $7 \mathrm{~km}$ coastline. The development of the village into one of the beach tourism destinations has been a long-term discourse, but until now it has not been implemented. To realize this, it is necessary to explore the development of supporting facilities in order to initiate the development of the village into a tourist destination mangrove tourism area. Seeing this reality, the USU PPM Implementation Team through the Professor Serves Program Scheme helped community problems by developing mangrove forest areas and providing supporting facilities, namely beach tourism park umbrellas. The existence of this facility is expected to help increase the carrying capacity of this newly formed tourist site. This program will encourage the spirit of the realization of mangrove tourism areas and be able to produce other downstream tourism products.
\end{abstract}

Keyword: Mangrove, tourism umbrellas, Regemuk village

\begin{abstract}
Abstrak
Desa Regemuk sangat potensial dikembangkan menjadi desa tujuan wisata baru. Desa yang terletak dengan garis pantai Kabupaten Deli Serdang ini secara geografis merupakan desa terdekat dengan Kota Medan dan lokasinya bersebelahan dengan Bandara Kuala Namu. Salah satu keunggulan desa ini adalah terdapatnya hamparan hutan mangrove yang tergolong masih cukup baik sepanjang garis pantai $7 \mathrm{~km}$. Pengembangan desa menjadi salah satu tujuan wisata pantai telah menjadi wacana cukup lama, namun hingga kini belum terlaksana. Untuk mewujudkannya maka perlu digali pengembangan fasilitas-fasilitas pendukung agar dapat menginisiasi pengembangan desa menjadi kawasan wisata mangrove tujuan wisata. Melihat kenyataan ini Tim Pelaksana PPM USU melalui Skema Program Profesor Mengabdi membantu permasalahan masyarakat dengan pengembangan kawasan hutan mangrove dan penyediaan fasilitas penunjang yaitu payung taman wisata pantai. Keberadaan fasilitas ini diharapkan dapat membantu meningkatkan daya dukung lokasi wisata yang baru terbentuk ini. Program ini akan mendorong semangat terwujudnya kawasan wisata mangrove serta mampu menghasilkan produk turunan hilir wisata lainnya.
\end{abstract}

Kata Kunci: Mangrove, payung wisata, desa Regemuk 


\section{PENDAhULUAN}

Kecamatan Pantai Labu merupakan salah satu dari 22 kecamatan yang ada di wilayah administrasi Kabupaten Deli Serdang, Provinsi Sumatera Utara. Salah satu desa pesisir yang berada di kecamatan ini adalah Desa Rugemuk. Desa Regemuk merupakan salah satu desa dari 17 desa dan 2 kelurahan yang ada di Kecamatan Pantai Labu yang terletak di pesisir pantai utara Provinsi Sumatera Utara dengan panjang pantai $2 \mathrm{~km}$ dengan luas hutan mangrove berkisar $7 \mathrm{Ha}$.

Sebagai desa pesisir di garis pantai utara Sumatera Utara, Desa Rugemuk memiliki wilayah pesisir berupa hamparan lumpur yang didominasi oleh vegetasi mangrove seperti bakau (Rhizopora mucronata), api-api (Avicenia alba), dan beberapa jenis mangrove lainnya. Secara ekologis mangrove mempunyai fungsi, sebagai penyedia nutrisi bagi biota perairan seperti ikan dan udang, tempat pemijahan (spawning ground) tempat mencari makan (feeding ground) dan tempat berkembang biak (nursery ground) bagi berbagai macam jenis biota air, tempat bersarangnya bebagai jenis burung dan lain-lain. Mangrove juga mempunyai fungsi fisik ,yaitu menjaga garis pantai dan tebing sungai agar tetap stabil, melindungi pantai dari erosi laut (abrasi), mengendalikan intrusi air laut, mempercepat perluasan lahan, pengolah bahan limbah organik, penahan amukan angin topan dan tsunami dan lain-lain. Selain kedua fungsi di atas hutan mangrove juga mempunyai fungsi ekonomi ,yaitu sebagai penghasil kayu sebagai sumber bahan bakar (arang, kayu bakar), bahan bangunan (balok, atap rumah, tikar), obat-obatan, minuman serta makanan, tannin dan lain-lain, pertambakan, tempat pembuatan garam, bahan bangunan dan lainlain.

Kondisi sosial ekonomi masyarakat Desa Regemuk pada umumnya tergolong miskin. Seperti halnya kebanyakan desa pesisir lainnya di Sumatera Utara, masyarakat umumnya memiliki mata pencaharian sebagai nelayan. Hanya sebagian kecil warga masyarakat desa ini yang berprofesi sebagai pedagang, pekerja, dll. Tingginya tingkat kemiskinan di desa ini disebabkan oleh beberapa faktor, antara lain : (1) Pendapatan masyarakat, khususnya nelayan bergantung pada kondisi alam, (2) Diversifikasi sumber mata pencaharian hampir tidak ada, (3) Penanganan pasca tangkap pada masyarakat nelayan sangat rendah (4) Masa panceklik yang selalu dan pasti datang setiap tahun (5) Kurangnya pemberdayaan masyarakat dalam program wirausaha berdasarkan potensi desa. Penanganan peningkatan perekonomian warga desa sangat terkait dengan potensi wilayah. Sebagai salah satu desa pantai yang terletak paling dekat dengan ibukota provinsi, desa ini sangat potensial untuk dikembangkan sebagai desa wisata mangrove. Potensi hutan mangrove yang terawat baik menjadi potensi wisata utama yang khas yang berbeda dibandingkan dengan desa pantai lainnya. Selain itu letak geografis yang paling dekat dengan Kota Medan, yakni berbatasan dengan bandara kebanggaan masyarakat Sumatera Utara yakni Kuala Namu menambah nilai lebih desa ini untuk dikembangkan menjadi desa ekowisata.

Tim Pelaksana PPM Profesor Mengabdi Tahun 2019 dari USU ke Desa Regemuk akan memberikan harapan baru bagi masyarakat. Masyarakat secara antusias mengeluhkan kondisi ini dan berharap tim pelaksana PPM USU untuk dapat membantu permasalahan warga ini. Hasil pemantauan Tim Pelaksana PPM pada beberapa rumah warga membuktikan keluhan warga ini. Oleh karena itu tim pelaksana PPM USU berencana untuk membantu mengatasi permasalahan warga ini melalui iptek yang dimiliki ditambah bekal pengalaman tim pelaksana PPM.

\section{METODE PELAKSANAAN}

Metode pendekatan yang ditawarkan bagi wilayah dan mitra sasaran adalah berupa:

a. Identifikasi permasalahan utama Desa Regemuk yang berada di wilayah Kecamatan Pantai Labu Kabupaten Deli Serdang Provinsi Sumatera Utara menggunakan metode forum group discussion (FGD).

b. Pendekatan pada masyarakat dan tokoh masyarakat untuk menawarkan program iptek yang diusulkan. 
c. Sosialisasi dan pemahaman perlunya program ipteks diterima di desa sasaran untuk peningkatan perekonomian masyarakat desa sasaran.

d. Pelatihan pada masyarakat tentang cara penggunaan serta perawatan alat iptek yang disumbangkan pada masyarakat.

e. Pelatihan dan pembelajaran pada masyarakat tentang cara pembuatan alat iptek yang disumbangkan sehingga masyarakat dapat membantu wilayah lainnya yang menghadapi permasalahan yang sama.

Kegiatan pembelajaran dilakukan dengan pemberian teori yang dilakukan sedemikan rupa sehingga mudah dipahami dan dimengerti oleh masyarakat. Penggunaan peralatan berupa LCD proyektor merupakan sarana vital yang akan digunakan, sehingga akan lebih menambah ketertarikan masyarakat tentang topik yang disampaikan. Adapun untuk kegiatan pembelajaran akan dilaksanakan melalui teori dan kegiatan aplikatif di lapangan yang akan dilakukan oleh masyarakat, mahasiswa dan dosen-dosen Universitas Sumatera Utara yang mempunyai kompetensi dengan bidang masing-masing kegiatan yang akan dilaksanakan.

\section{HASIL DAN PEMBAHASAN}

Kegiatan pengabdian masyarakat didahului dengan menggunakan metode focused discussion group (FGD) yang melibatkan masyarakat desa sasaran berikut tokoh masyarakat dan kepala desa dan aparat desa. Kegiatan selanjutnya adalah survei dan peninjauan Kawasan pantai yang akan dikembangkan menjadi Kawasan wisata hutan mangrove di Desa Regemuk Kecamatan Pantai Labu Kabupaten Deli Serdang.

Hasil survei menunjukkan bahwa Kawasan pantai yang akan dikembangkan masih harus dipersiapkan, baik dari segi sarana, prasarana dan sanitasi. Hutan mangrove di sekitar lokasi mengalami kerusakan akibat kurangnya kesadaran masyarakat untuk memelihara hutan dan abrasi. Persoalan sampah adalah sesuatu yang berhubungan langsung dengan keindahan dan kebersihan lingkungan baik didaratan maupun dipesisir pantai. Lemahnya kesadaran masyarakat karna membuang sampah bukan ditempat sampah, mengakibatkan lingkungan sekitar termasuk pantai dan hutan bakau (mangrove) terkena dampaknya.

Untuk mempersiapkan kawasan pantai yang akan dikembangnya menjadi Kawasan wisata hutan mangrove, tim pelaksana pengabdian kepada masyarakat beserta perangkat desa dan masyarakat secara bersama-sama memberbersihkan Kawasan pantai dari sampah dan membuat jalan masuk ke ke Kawasan tersebut. Melalaui pendekatan persuasif dari tim pelaksana kegiatan pengabdian masyarakat dan perangkat desa Regemuk kegiatan ini dapat berlangsung dengan baik dan kawasan pantai terlihat lebih bersih dan rapi serta telah tersedia jalan masuk untuk mempermudah akses menunjuk kawasan pantai tersebut.

Mangrove merupakan jenis tanaman yang hidup dan tumbuh disekitar pasang surut pantai, jadi pertumbuhan pohon jenis ini sangat bergantung oleh pasang surut air laut. Banyak masyarakat yang salah dalam mengartikan hutan bakau untuk mangrove, karena istilah bakau sendiri merupakan salah satu spesies penyusunan hutan mangrove yaitu Rhizophora sp, sedang untuk istilah mangrove itu sendiri ditujukan untuk segala tanaman tropis yang memiliki karateristik dalam hidup dan tumbuh di daerah pinggiran pantai.

Belakangan ini kawasan hutan mangrove mengalami penurunan dikarenakan pengetahuan masyarakat akan pentingnya manfaat pohon mangrove yang kurang, tidak mengetahui dan atau tidak mengerti cara pembibitannya. Faktor kerusakan yang sangat besar adalah pembukaan tambak udang, ikan, garam besar-besaran secara modern dengan menggunakan escapator (beco), pembangunan pemukiman, industri dan basih banyaknya dapur arang yang masih berproduksi. Penanaman mangrove dapat dilakukan dengan 2 (dua) cara yaitu cara penanaman langsung buah mangrove (propagul) dan melalui persemaian bibit. Tingkat kelulusan hidup penanaman langsung relatif rendah yaitu sekitar $20-30 \%$, hal ini disebabkan pengaruh predator dan pengaruh arus waktu pasang surut, dengan cara persemaian dan pembibitan tingkat kelulusan hidup relatif tinggi sekitar $60-80 \%$. 
Kelengkapan sarana dan prasarana merupakan salah satu daya tarik pengunjung untuk datang ke suatu kawasan wisata. Pembuatan payung wisata yang akan dipasang di kawasan pantai mangrove merupakan kegiatan yang dapat dilakukan masyarakat desa Regemuk bekerja sama dengan tim pelaksanaan kegiatan pengabdian masyarakat USU. Tim pelaksana menyediakan bahan serta peralatan yang dibutuhkan untuk proses pembuatan payung wisata. Pembuatan payung dibimbing oleh tenaga terampil pada bengkel las setempat yang membantu masyarakat dalam proses pengelasan payung wisata tersebut.

Kegiatan ini diikuti dengan antusias karena masyarakat meyakini bahwa payung wisata yang akan dipasang di Kawasan pantai Regemuk nantinya akan menjadi daya tarik bagi pengunjung. Pelatihan dalam pembuatan payung wisata ini juga dapat bermanfaat untuk menambah keterampilan masyarakat yang dapat terus dikembangkan hingga dapat menjadi penghasilan tambahan.
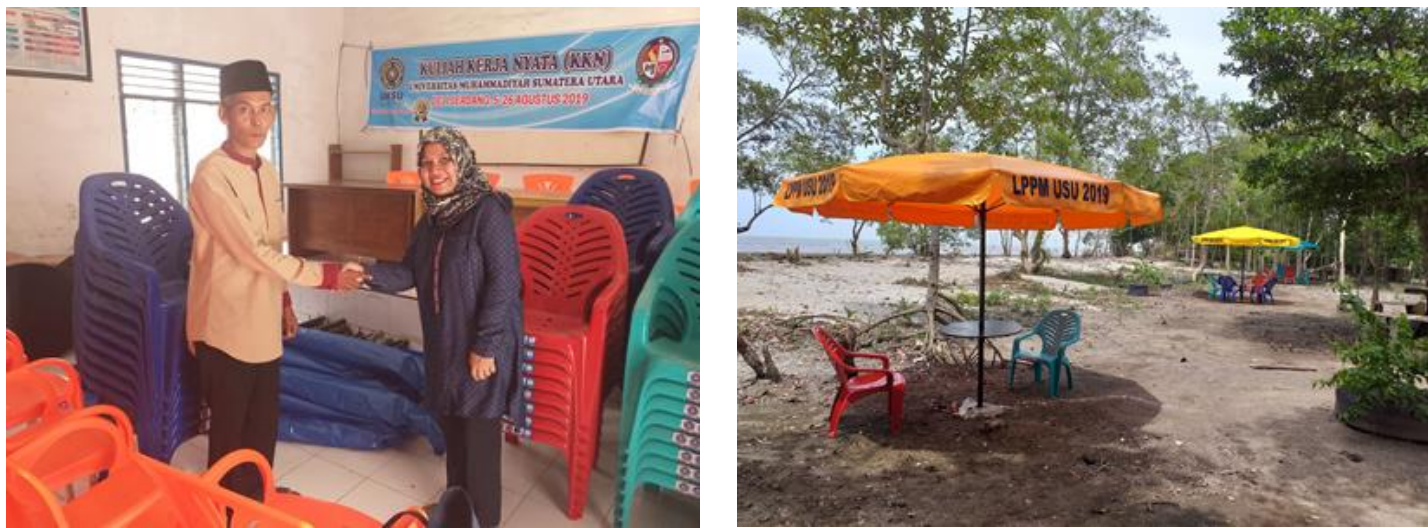

Gambar 3.1 Serah terima payung dan pemasangan payung di pantai

Payung wisata yang telah dirakit sebanyak 15 unit selanjutnya dipasang di pantai desa Regemuk bersama-sama dengan masyarakat, perangkat desa dan tim pelaksana pengabdian masyarakat USU. Payung yang telah terpasang dilengkapi dengan kursi santai sebanyak 4 buah kursi pada setiap payung. Kursi santai yang diserahkan kepada mitra sebanyak 60 buah. Dengan adanya fasilitas payung wisata dilengkapi dengan kursi diharapkan dapat meningkatkan minat wisatawan untuk berkunjung ke pantai mangrove di Desa Regemuk.
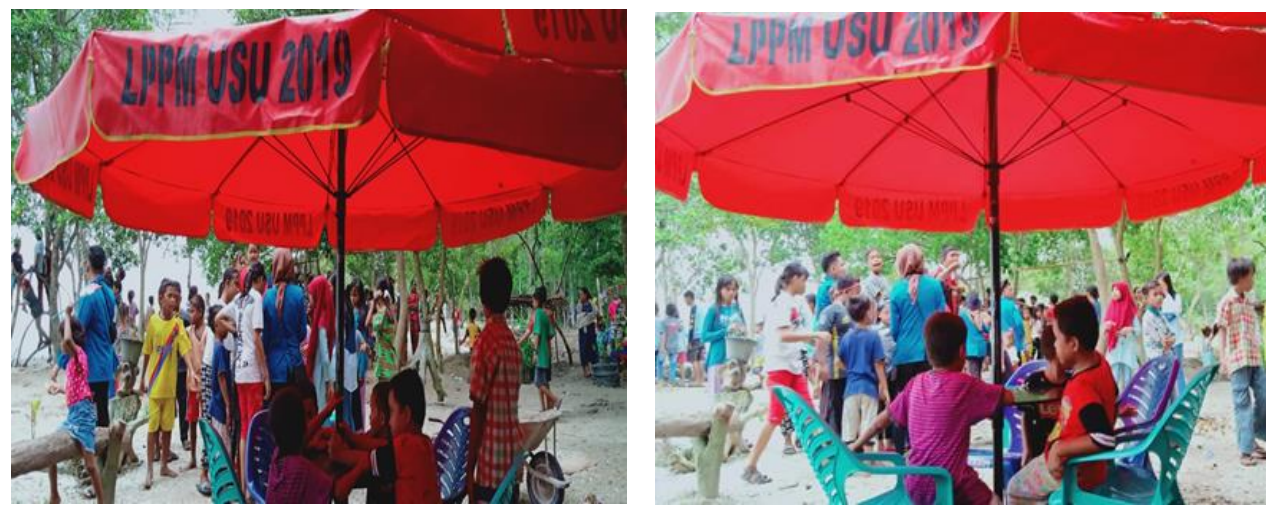

Gambar 3.2 Kunjungan masyaraat ke pantai mangrove

Menurut Undang-Undang Republik Indonesia Nomor 10 Tahun 2009 tentang kepariwisataan disebutkan bahwa pariwisata adalah berbagai macam kegiatan wisata dan didukung berbagai fasilitas serta layanan yang disediakan oleh masyarakat, pengusaha, pemerintah, dan pemerintah daerah. Kegiatan pariwisata harus didukung tersedianya prasana umum dan fasilitas pariwisata. Prasarana umum adalah kelengkapan dasar fisik suatu lingkungan yang pengadaannya memungkinkan suatu lingkungan dapat beroperasi dan berfungsi sebagaimana semestinya, 
sedangkan fasilitas pariwisata adalah semua jenis sarana yang secara khusus ditujukan untuk mendukung penciptaan kemudahan, kenyamanan, keselamatan wisatawan dalam melakukan kunjungan ke destinasi pariwisata.

Masyarakat di sekitar objek wisatalah yang akan menyambut kehadiran wisatawan tersebut dan sekaligus akan memberikan layanan yang diperlukan oleh para wisatawan. Untuk ini masyarakat di sekitar objek wisata perlu mengetahui berbagai jenis dan kualitas layanan yang dibutuhkan oleh para wisatawan. Dalam hal ini pemerintah melalui instansi-instansi terkait telah menyelenggarakan berbagai penyuluhan kepada masyarakat. Salah satunya adalah dalam bentuk bina masyarakat sadar wisata. Dengan terbinanya masyarakat yang sadar wisata akan berdampak positif karena mereka akan memperoleh keuntungan dari wisatawan yang membelanjakan uangnya. Para wisatawan akan untung karena mendapat pelayanan yang memadai dan juga mendapatkan berbagai kemudahan dalam memenuhi kebutuhannya.Tim pelaksana kegiatan pengabdian kepada masyarakat telah melaksanakan kegiatan ceramah dan praktek pemeliharaan fasilitas penunjang wisata di pantai Desa Regemuk Kecamatan Pantai Labu Kabupaten Deli Serdang.

\section{KESIMPULAN}

Dari hasil kegiatan pengabdian kepada masyarakat yang telah dilaksanakan oleh tim pengabdi dapat disimpulkan bahwa :

1. Payung wisata yang telah dirakit sebanyak 15 unit dan dipasang di pantai desa Regemuk bersama-sama dengan masyarakat, perangkat desa dan tim pelaksana pengabdian masyarakat USU

2. Payung yang telah terpasang dilengkapi dengan kursi santai sebanyak 4 buah kursi pada setiap payung.

3. Kursi santai yang diserahkan kepada mitra sebanyak 60 buah.

\section{UCAPAN TERIMAKASIH}

Tim pengabdian pada masyarakat mengucapkan terima kasih kepada LPPM USU yang telah memberikan dana kepada pengabdian ini. Terima kasih juga kepada pihak mitra yang telah kooperatif di dalam pelaksanaan pengandian ini.

\section{DAFTAR PUSTAKA}

Arfianto AEW dan Balahmar ARU. 2014. Pemberdayaan Masyarakat dalam Pembangunan Ekonomi Desa. JKMP 2:1 1-93.

Badollahi A. 2013. Menuju Pembangunan Desa 2015-2019. Arah Kebijakan Nasional dan Strategi Pengembangan Wilayah Pedesaan. http://media.kompasiana.com/buku/2014/10/31/ menujupembangunan-desa-2015-2019-684013.html

Badan Pusat Statistik. 2016. Kabupaten Deli Serdang dalam Angka tahun 2016. Seri Publikasi Tahunan BPS Kabupaten Deli Serdang Provinsi Sumatera Utara.

Lembaga pengabdian pada masyarakat. 2016. Program kegiatan. http://usu.ac.id/id/ (diakses pada 05 November 2017).

[PAMSIMAS] . 2015. Perencanaan dan Konstruksi Payung taman wisata. Program Penyediaan Fasilitas Kawasan Wisata Berbasis Masyarakat. Https://beta.new.pamsimas.org/. (diakses pada 12 November 2017). 
ISSN Printed Version: 2549-4341

ISSN Online Version: 2549-418X

ABDIMAS TALENTA 4 (2) 2019: 558-563

http://abdimas.usu.ac.id

Darma Bakti, et.al. Development of mangrove tourism

[USU]. Universitas Sumatera Utara. 2017. Fasilitas dan sumber. http://lppmusu.ac.id/id/ (diakses pada 05 November 2017). 